\title{
Preface
}

THE Republic of the Sudan obtained its full independence from the Anglo-Egyptian condominium rule in 1956. It is a highly heterogeneous nation composed of several widely divergent cultures, and at least five major cultural areas extend into the country. In the east, on the coast, and in the Red Sea Hills, are the Beja; in the far west, centered in Darfur Province, are various peoples whose cultural affiliation is with the Negroid cattle herders who range westward along the southern edge of the Sahara Desert; in the south are Nilotic tribes and Nilo-Hamitic peoples; and in isolated mountain areas of southern Kordofan Province are the Nuba Hill peoples. Just to the east of them live the Fung. Nubians reside along the Nile from Aswan in Egypt to Dongola in the Sudan, and the remaining areas-the north and central Sudan—are inhabited by Arabs, who comprise about half the population of the country. All these groups, except for the pagan southerners and the Nuba Hill and Fung peoples, are Muslims by religion. (Thus, possibly 70 per cent of the population is Muslim.) All of them, whether Arab or Nilotic or Darfur, belong to tribal groups, subdivisions of their overall cultural groups. Arab influence is observable and Arabs themselves reside in scattered numbers almost everywhere in northern Sudan. The greatest contrast is then between the north (comprising the provinces of Kassala, Northern, Khartoum, Kordofan, Darfur, 
and Blue Nile) and the south (comprising the provinces of Upper Nile, Bahr El Ghazal, and Equatoria)-the home of numerous Negro pagan tribes.

Within the Arab Sudan itself there are definite subareas with major differences relating to ecological and economic patterns. Thus, there are the essentially nomadic groups divided between the camel herders in the northern desert regions and the cattle herders in the southern central areas, where there is more rainfall. There are essentially sedentary groups comprising those who live along the Nile, cultivate primarily by means of irrigation, and maintain livestock as a subsidiary and also those who live in a belt across the middle of the Sudan, where rainfall is sufficient to permit dependence upon rain cultivation. In addition, there are seminomadic peoples who, although they maintain permanent villages, spend more than half the year some distance from their homes pasturing their livestock.

About 20 per cent of the people in the Sudan are Arab sedentary villagers living along the banks of the Nile or in irrigation areas watered by the Nile through a system such as the Gezira Scheme. Almost an equal number are rain cultivators, so that the total number of Arab nomads is hardly Io per cent of the population. Most of these are Baggaara, or cattle herders. ${ }^{1}$

Map I shows the general distribution of the Arab subcultural areas in the Sudan.

Most of those who claim to be Arabs are in fact Arabized Nubians-descendants of the indigenous Nubian riverain population, who in the course of the last four hundred years have adopted the Arabic language, Islamic faith, and other important elements of Arab culture. Racially they are a highly mixed group, exhibiting

${ }^{1}$ In the Sudan the term Baggaara is reserved for those seminomadic or nomadic Juhayna tribes "lying south of the thirteenth parallel of latitude and stretching from the White Nile to Lake Chad" (Harold A. MacMichael, $A$ History of the Arabs in the Sudan [London: Cambridge University Press, 1922 ], I, 171). Murdock errs in using the term to include camel nomads and Nile cultivators as well as cattle nomads (George P. Murdock, Africa: Its Peoples and Their Culture History [New York: McGraw-Hill, 1959], p. 410).

For an explanation of the transliteration of Arabic in this text see Appendix A, "A Note on the Transliteration of Arabic." 
both Negroid and Caucasoid features. Their skin pigmentation varies from a yellowish coloration to a chocolate brown, with the great majority tending toward the latter. Their hair is black, varying from wavy to kinky. Many exhibit such Negroid features as thick protruding lips, flat broad noses, and prognathism, but it was the writer's impression that Caucasoid facial features are more characteristic, at least in the vicinity of Khartoum and northward. The Baggaara, however, are extremely Negroid. It is not uncommon to find an Arab Sudanese with pronounced Caucasoid facial features -narrow, pointed nose and thin lips-and extremely dark skin pigmentation.

This work is a revision of the writer's doctoral thesis of $196 \mathrm{I}$ for Cornell University. It does not pretend to deal with the entire Arab Sudan but, rather, has as a more modest aim the ethnographic description of one example of this culture-Buurri al Lamaab, a village in the Khartoum suburbs. A "complete" description of the village will not be found in these pages, but it is hoped that what is presented will be sufficient to give the reader a substantial picture of, and a feeling for, Arab Sudanese culture as manifested in this community.

The selection of items for description and the determination of the extent to which they are described are based on several considerations. First, an attempt has been made to cover the anthropologically significant units of description, as is indicated in the Contents. Second, such coverage is limited by the length of time devoted to the study, by what the writer is capable of describing, and also by his own personal interests. Finally, much ultimately depends upon the kinds of information that informants and the general cultural circumstances permit the anthropologist to gather.

Although this study attempts to present relevant data concerning all the various institutional complexes in the village, it focuses chiefly on family and kinship organization and religion, with the underlying purpose of seeking to demonstrate the kinds of changes which this village at the edge of a major urban center is undergoing.

The material has been presented according to the traditional pattern of ethnographies, that is, including economics, political organi- 
zation, family and kinship, and so on. No particular brief is made for this format. It often tends to be arbitrary; it tends to de-emphasize functional interrelationships and the numerous themes that cut across institutional lines. Nevertheless, it has the advantage of being more or less established procedure, which therefore more easily permits comparison of one ethnography with another-all using approximately similar categories. In addition, though it may be argued that certain other ways of presenting anthropological data may be as good, none are really superior, for all are hampered with difficulties of categorization.

\section{Methodological Techniques}

The bulk of the data was gathered from key informants. The author spent much time with two men in particular, both middleaged, lifelong residents, descended from founders of the village. Many hours were spent also with each of the twenty-seven other informants. The writer's wife interviewed six women of the village, obtaining materials which in this culture only a woman may gather. Additional information was secured through observation, through "passing the time of day" with different men at one of the local clubs or with men gathered at a street corner, by attending various village ceremonies and meetings, or by sitting around drinking tea with villagers. An attempt was made to review materials in the Sudan archives relevant to Buurri al Lamaab. This effort, however, was begun late in the study and because of various complications did not bring results.

The eleven months of research in the village was begun at the end of April, 1959, and continued through the end of March, 1960. ${ }^{2}$ It is one of the shortcomings of this study that the writer was not able to take up residence in the village but was required by the Sudan government to reside in the nearby city of Khartoum. This restriction by the Sudanese authorities apparently was largely a result of the political situation in the country at the time research was begun. In November, 1958, there was a military coup d'état, and all during the following spring, while permission to conduct the

${ }^{2}$ However, a total of fifteen months was spent in the Sudan following a stay of two and one-half years in Egypt. 
research was pending, the new regime was extremely unstable, with rumors of revolt and one attempted coup. This situation was further complicated by the fact that the writer was an independent researcher unaffiliated with any Sudanese or international organization and was the first American anthropologist to seek to undertake research in this region.

The village was visited from five to seven days of the week for from three to seven hours a day, and occasionally the night was spent there. The disadvantages of this kind of arrangement should be obvious, but the extent to which it is a disadvantage may be a question. Visiting the village each day, sitting around talking to people, attending their funeral mournings, weddings, and other activities, joining one of the clubs and teaching in $i{ }^{3}{ }^{3}$ and visiting their homes -all these activities are in themselves more than the villagers expect of a Westerner and are sufficient to obtain for him some measure of rapport with the people. The villagers' experience with Westernersmainly the British-has been such that they do not expect or require a Westerner to become Sudanese when among them. As a result they are usually pleased when the Westerner accepts invitations to their homes or to eat with them. Those villagers who have been most exposed to the British colonial's aloof character are often responsive to a friendly Westerner. The Arab Sudanese are a suspicious people, but they are extroverts; they like to gossip about others, and once a stranger is identified with someone respected and familiar they tend on the whole to become friendly. These are some of the reasons why living outside the village may not have raised as many difficulties here as it might have in some other cultural situation. Nevertheless, after working in Buurri al Lamaab a few months, the writer found that he was frequently asked why he did not live in Buurri al Lamaab. In addition, his residence in Khartoum made it more difficult to reciprocate the hospitality of the villagers.

For the first three months of the study the writer engaged an interpreter from Khartoum who was acquainted with some of the inhabitants of the village; this mitigated the problem of entering

${ }^{3}$ The Buurri al Lamaab Cultural Club sponsored an elementary English class which the writer volunteered to conduct during the latter half of his stay in the Sudan. 
Buurri al Lamaab and gaining rapport. For the remainder of the research the writer depended on his own knowledge of Arabic and occasional assistance from villagers who understand English. ${ }^{4}$

No informant was ever paid for his services and none ever asked to be paid. Gifts were made to informants, especially in the form of household items, food, and photographs. Needless to say, the ethnographer's debt has not been fully repaid.

In this description I have tried to be as objective and dispassionate as possible and have sought to avoid partisanism in dealing with the factional differences in the village. If I have dealt with anyone or any group unfairly, it has not been intentional, and I ask to be forgiven.

\section{Selection of the Village for Study}

The original intention was to investigate a riverain Arab village in the north central Sudan somewhat more removed from the major urban centers, but owing to the restrictions of the Sudanese government on the research project and the difficulties of transportation in the country it was necessary to select a village in the immediate vicinity of Khartoum. Buurri al Lamaab was chosen because it was easily accessible to Khartoum though outside the Khartoum municipality and because it was the center for a religious brotherhood. This study cannot pretend to deal with a "typical" riverain Sudanese Arab village, if such exists; Buurri al Lamaab is probably not even a typical suburban village in this area, since it is the main headquarters of the Hindiiya Religious Brotherhood. Nevertheless, major patterns characteristic of the riverain Arabs of the Sudan are to be found in Buurri al Lamaab, especially in the rites of passage, the marriage and residence patterns, the overall family structure, and the political and religious organization. Its most pronounced atypicality may be observed in its economy and the heterogeneity of its population and in other consequences of being close to a major urban

"Sixty years of British administration and the compulsory English courses in all schools from the fifth year up have resulted in a rather high proportion of Sudanese who speak English, particularly in the Khartoum area. In Buurri al Lamaab at least twenty men could converse in varying degrees in this language; an equal number understood a considerable amount of English but did not speak it. The writer's two main informants understood many English words although they were unable to speak the language. Interviews with twenty-five informants were carried on in Arabic and with the remaining four in English. 
center. These points will be expanded in the course of the description of the village.

The writer wishes to express his thanks and appreciation to those who have been of assistance to him. He is especially grateful to all those in Buurri al Lamaab who extended their typical Sudanese hospitality to him and his wife and who patiently tolerated his blundering attempts to express himself in their language. Financial support was obtained from the Social Research Center at the American University at Cairo in the United Arab Republic, and special thanks are due the director of the Center, Dr. Laila Shukry El Hamamsy, for her part in securing the necessary funds and for encouraging the author. The writer is also obligated to Dr. Andreas Kronenberg of the Sudan Antiquities Service and to the University of Khartoum, especially to the late Professor Saad ad Din Fawzy, to Mr. Farnham Rehfisch, and to Mr. Muhammad Umar Bashir, for their assistance while he was in Khartoum. Mr. Ahmad Osman Ishaq, acting director of the Sudan Census, Khartoum, very graciously provided unpublished census data on Buurri al Lamaab. Professors Robert J. Smith, Gordon F. Streib, and Olaf F. Larson of Cornell University offered numerous helpful suggestions concerning the preparation of this work. And finally the writer is particularly obligated to his wife, Jane, who collected the bulk of the data on the Sudanese women and was of invaluable assistance in writing this book.

H. B.

June 1963 
